\title{
e-Parking: Multi-agent Smart Parking Platform for Dynamic Pricing and Reservation Sharing Service
}

\author{
Bassma Jioudi ${ }^{1}$, Aroua Amari ${ }^{2}$, Fouad Moutaouakkil ${ }^{3}$, Hicham Medromi ${ }^{4}$ \\ Research Foundation for Development and Innovation in Science and Engineering, Engineering research laboratory (LRI) \\ System Architecture Team (EAS) National and High School of Electricity and Mechanic (ENSEM) \\ Hassan II University, Casablanca, Morocco
}

\begin{abstract}
Parking is a key element of a sustainable urban mobility policy. It plays a fundamental role in travel planning and transport management, as the foremost vector of modal choice, but also as a potential means of freeing up public spaces. In this article we define the smart parking concept, as an application of smart mobility, present a historical analysis of the evolution of smart parking framework and show a statistical analysis of the published patent applications in this field around the world using the ORBIT database. Then, we propose a new smart parking architecture based on multi-agent features. Finally, we introduce the e-Parking system, platform to improve the driver experience of crowded cities. It provides real-time parking prices and offers a reservation and guidance services. In addition, the system assigns an optimal parking for a driver based on the user's requirements that combine proximity to destination, parking cost and dwell time, while ensuring a fair sharing of public space among users and improves traffic conditions. Our approach is based on dynamic pricing policy. Our scheme is suitable for mixed-usage areas, as it considers the presence of reserved and not reserved driver in the same parking area.
\end{abstract}

Keywords-Smart cities; smart mobility; smart parking; dynamic pricing policy; cruising traffic

\section{INTRODUCTION}

Throughout the 20th century, the private car is gradually becoming the most favorable transport mode. Mobility experts predict that the number of motor vehicles in densely populated areas will increase significantly over the last 30 years which will greatly change the way the territory is managed. The mostly influenced element by this change is parking.

Indeed, urban areas suffer from increasing traffic congestion, followed by economic, social and environmental damage. In addition, in areas where parking capacity is limited and parking information is not available, the situation becomes more challenged.

Moreover, the lack of parking spaces combined with inefficient parking pricing policies increase the difficulty of finding available parking spaces, induce additional traffic congestion and increase the environmental impact of car journeys [1]. Surprisingly, Shoup [2] found that about 8 to $74 \%$ of traffic in Central Business Districts (CBD) is due to vehicles looking for parking spaces and the average time to find an available space is about 3.5 to $14 \mathrm{~min}$.

Known as one of the leading causes of congestion in big cities, looking for available parking spaces process has attracted many authors [1]-[10]. The common objective of these works is to reduce as much as possible the time lost in searching for an available place and eliminate the negative consequences on the urban environment and the quality of life.

However, the large number of drivers looking for parking spaces is mainly due to:

- Lack of parking information, so that drivers conduct blind research to find an available parking lot;

- Driver preferences for free or cheap parking lots. So that they move away from the off-street parking to go to the on-street parking lots, which causes many problems of urban traffic;

- Drivers who occupy attractive parking lots for a long time (commuters) and prevent the rotation of parking spaces. Indeed, commuters who arrive early, take the attractive parking places and drivers arriving during the day do not find places available near to their destinations.

To address these problems, we may introduce smart parking solutions, through guidance and booking services. However, this type of solution has some limitations:

- Driver should be informed that the target area only receives customers who have booked in advance, in order to avoid additional flows (drivers without reservations);

- Driver should control his parking dwell time to avoid overcharging;

- Another problem with reservation systems is the phenomenon of multiple-car-chasing-single space, so that the customer who arrives and finds his place occupied by the last driver who has parked previously or by another who has not reserved; and no place is available in the parking, will be asked to leave without parking, which would cause frustration among drivers;

- In order to guide a driver to a vacant space, an availability parking detection system is required. However, the cost of implementing such a heavy solution is important, especially on the streets, given the number of equipment to be installed per lot (sensors, cameras, retractable bollards, etc.). 
Based on the above findings, pricing policies are obviously an effective control tool to reduce the search for parking spaces and control parking occupancy and dwell time. In this article, we focus on the smart parking concept as an application of urban mobility that aims to resolve traffic problems. We present a historical analysis of the evolution of the concept and statistical analysis of the published patent applications for smart parking in the ORBIT database around the world. Then, we discuss our proposed smart parking architecture based on multi-agent features. Finally, we highlight the features and services of a Smart parking Web application developed in the Foundation of Research, Development and Innovation in Sciences and Engineering of Casablanca, Morocco (FRDISI). The proposed concept aims to improve the driver experience by combing real time pricing and reservation sharing service.

This article is organized as following: In Section II, analysis of smart parking concept and paper problematic are presented. In Section III, we are interested to the proposed solution architecture and the role of each agent in the system. Then, in Section IV, we present the e-Parking smart parking platform and the different steps that user can be experienced. Lastly, we conclude our work.

\section{STATE OF ART}

The degree of urbanization in the world is continuously increasing. According to the United Nations forecasts, increasing of urbanization combined with demographic growth will contribute to an increase in the population of cities by 2.5 billion people. In 2013, 50\% of the world's population lives in cities, and this proportion is expected to reach $70 \%$ in 2050 [11]. In the report on demography in Morocco, elaborated by the Center for Demographic Studies and Research (CERED) [12], it is estimated that Morocco will reach its stationary population (45 million inhabitants) by the year 2050. Overall, during the century from 1960 to 2060, the urban population of Morocco would be multiplied by 10 . The rate of urbanization which was $29.2 \%$ in 1960 would then be $71.6 \%$ according to these projections [13]. This is mainly due to the natural and migratory movements, the urban population increased rate, which creates unprecedented opportunities, but also new difficulties in urban management, that can lead to a strengthening of environmental degradation, poverty and exclusion [4].

In view of these findings, it is imperative for the authorities to develop new approaches and take the necessary measures to implement a territorial development policy to find new reception possibilities, ensure balanced spatial sharing of the population and related economic activities, reduce the environmental impact of cities, which make cities more intelligent and sustainable. This has given rise to the emergence of the smart city concept.

Smart cities constitute a priority concern for large cities leaders, both for the economic development of territories and for the well-being and living environment of citizens. A smart city stands out as a city that takes full advantage of digital transformation as well as Information and Communication Technologies (ICT) to improve public services and make them more personalized and efficient. As a concept, Smart City aims to provide a comprehensive state-of-the-art service platform that aims to improve the quality of life of citizens and the services offered by cities through the adequacy of existing infrastructure, citizen participation and, ultimately, to enable sustainable development of the urban environment in the future [14]-[16]. Article [17] presents the different definitions proposed and states that the concept of a smart city is no longer limited to the diffusion of ICT but consider the needs of citizens and communities.

Given the variety of definitions of the smart city, the report [14] summarizes the different domains and sub-domains identified in the literature according to six dimensions. In line with our research focus, smart mobility is based on the integration of ICT infrastructure, sustainable transportation and logistics systems to support improved urban mobility and prosperity of the urban environment. It allows to: notify drivers in advance of road dangers before they become visible; improve driver safety, for example by keeping vehicles at a safe distance from each other by suggesting optimal speed based on various parameters related to traffic conditions; use communications, including vehicle-to-vehicle (V2V) and vehicle-to-infrastructure (V2I) as special cases; inform drivers of the local speed limit; share information specific to an area (parking lots, petrol stations, etc.); provide users with real-time information on public transport services and real-time travel and traffic information, as well as intelligent and transparent ticketing solutions; enable users to plan their trip in a multimodal way; meet the needs of freight operators and customs authorities, this is accompanied by tracking the position and condition of shipments, as well as the orientation of their vehicles along the most efficient, economical and safe route; maximize vehicle efficiency and reduce $\mathrm{CO} 2$ emissions by choosing the optimal route and speed to the destination.

Global trends in urbanization and motorization and the influence on climate change make urban mobility sector a challenging task for traffic planners. The major element that the automobile has changed in the use of the ground is parking.

Parking constitutes one of the sources of environmental nuisance and degradation of living environment. This is particularly the case in dense urban areas where the lack of free places significantly affects the fluidity and traffic conditions due to drivers looking for parking space. Beyond these externalities, parking poses significant issues related to land use, occupying public space, pedestrian safety and social equity and it strongly determines the accessibility to different urban functions.

Companies and investors consider parking as an economic necessity and an important opportunity to attract customers to their business. A convenient parking offer is also necessary to retain staff and employees. In the sense that drivers always want to park as close as possible to their destinations, while ensuring safety at the best possible cost. City residences consider parking with a certain degree of emotion. They consider the space near to their residence as private property. From a pedestrian perspective, parking may be undesirable if it blocks walking trails or increases walking distances. Pedestrian safety is also challenged by unplanned or poorly designed parking lots. 
Today it seems admitted by authorities and transport planners that parking issues are much more complex and go beyond the simple lack of parking supply. However, due to the increasing demand for parking spaces in cities, finding a parking space is becoming a common challenge faced by millions of drivers every day. Although vehicles are stationary for $95 \%$ of the time, and therefore park for most of their life [18], the severe shortage of parking places has created a challenge and problem in managing these areas.

In article [19], four methods of searching parking spaces are cited: blind search (the most common method), the parking information sharing, buffer parking information sharing [20] and reservation-based smart parking systems [21]-[23]. Each of these methods has advantages and conveniences. The last three methods rely on the integration of information technology into the parking process via smart parking platforms.

Smart parking, application of smart mobility in smart cities, represents a potential solution to solve traffic and parking problem. Smart parking roles and key features have been widely discussed in the literature (see, for example, [3], [7], [24]-[33]) in recent years.

\section{A. Smart Parking Systems}

Smart parking system is becoming an alternative solution to solve parking problems. Fig. 1 illustrates the main components of a smart parking system:

Vehicle entry/ exit detection system: Identification of vehicles in checkpoints is the act by which a vehicle is authorized to enter/exit a restricted area. It is based on the detection of an identifier (i.e. the license plate of the vehicle) and compare it with a pre-established database. Access to the parking is generally managed by issuing a ticket with a digital code or bar code that has a configurable exit time or by the automatic identification of the driver through a token or a specific card. It facilitates several operations such as access control by validating, for example, access only to vehicles already reserved or payment of parking fees by recording the access and exit time of vehicles. Several technologies may be used to identify vehicles. We distinguish.

- Methods that require vehicles to be equipped with embedded devices (RFID, Bluetooth, NFC, etc.);

- Methods that potentially identify all vehicles without installing equipment in vehicles i.e. ALPR technology as an effective solution for identification since each vehicle has unique information.

Vacant parking lot detection system: The monitoring of parking spaces can be used to notify the driver of the number of places available in a parking, to guide drivers to the vacant places and to offer the service of reservation. Techniques can be divided into two types: the first suggests estimating the overall status of the parking, for example by counting incoming vehicles; the second supports the verification of the presence of a vehicle in each parking space to guide drivers to vacant places.

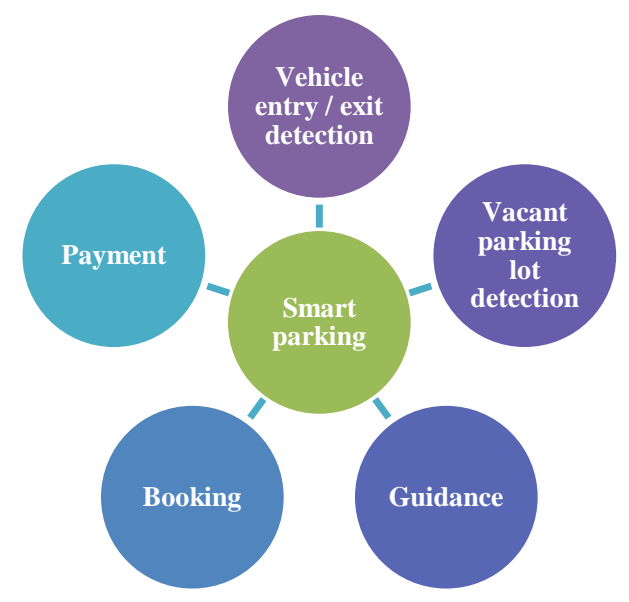

Fig. 1. Smart Parking Components.

Table I illustrates some of vacant parking detection systems and their implementation exigences.

Guidance system: Informs drivers about the availability of parking spaces in real time, via two tools: a mobile application and/or dynamic information panels. It informs drivers about parking capacity, price, parking levels, availability of spaces, directions to vacant spaces. The status of the parking spaces, identified via a detection element, is transmitted in real time to the central data processing and management system, which updates the variable message signs using digital network communications.

In order to ensure clear visibility, the choice of the placement of information signs panels in a parking is essential. Table II shows the types of signs that can be used in parking.

TABLE. I. VACANT PARKING DETECTION RESOURCES

\begin{tabular}{|l|l|l|l|}
\hline Resources & $\begin{array}{l}\text { Implementation } \\
\text { environment }\end{array}$ & Installation & $\begin{array}{l}\text { Detection } \\
\text { type }\end{array}$ \\
\hline $\begin{array}{l}\text { Radar } \\
\text { sensors }\end{array}$ & $\begin{array}{l}\text { On-street lots, } \\
\text { Open outdoor parking } \\
\text { lot, Covered parking } \\
\text { with high ceiling }\end{array}$ & $\begin{array}{l}\text { Urban lighting } \\
\text { columns, facade }\end{array}$ & $\begin{array}{l}\text { RADAR, no } \\
\text { image } \\
\text { acquisition. }\end{array}$ \\
\hline $\begin{array}{l}\text { Indoor } \\
\text { sensors }\end{array}$ & $\begin{array}{l}\text { For all underground } \\
\text { parking lots }\end{array}$ & Parking Ceiling & Ultrasonic \\
\hline $\begin{array}{l}\text { Outdoor } \\
\text { sensors }\end{array}$ & Ground & $\begin{array}{l}\text { on the ground } \\
\text { either Semi- } \\
\text { recessed, recessed } \\
\text { or surface } \\
\text { mounted }\end{array}$ & $\begin{array}{l}\text { Infrared, } \\
\text { magnetic }\end{array}$ \\
\hline $\begin{array}{l}\text { Camera } \\
\text { large-scale parking }\end{array}$ & $\begin{array}{l}\text { on building or } \\
\text { high mast }\end{array}$ & $\begin{array}{l}\text { Image } \\
\text { acquisition } \\
\text { and } \\
\text { processing }\end{array}$ \\
\hline $\begin{array}{l}\text { Minute stop } \\
\text { station }\end{array}$ & $\begin{array}{l}\text { On-street lots, } \\
\text { aeoroports, private } \\
\text { areas }\end{array}$ & On street ground & Magnetic \\
\hline $\begin{array}{l}\text { Combined } \\
\text { technologies }\end{array}$ & $\begin{array}{l}\text { Combination of more than one detection resource, e. g. video } \\
\text { camera and indoor sensors. }\end{array}$ \\
\hline
\end{tabular}


TABLE. II. THE TYPES OF SIGNS IN PARKING.

\begin{tabular}{|l|l|}
\hline Types & Description \\
\hline Plinth external signs & $\begin{array}{l}\text { Double or single-sided signage mounted on the } \\
\text { ground or on a wall and generally used at the } \\
\text { entrances of multi-level parking, or at the end of the } \\
\text { aisles of outdoor parking }\end{array}$ \\
\hline Wall signs & Provide directions and/or place numbers \\
\hline LED light panels & $\begin{array}{l}\text { Designed for internal marking and mounted on the } \\
\text { ceiling }\end{array}$ \\
\hline Application mobile & Installed on a mobile device or on-board computer \\
\hline
\end{tabular}

Booking system: Booking or Reservation is the action of retaining an empty place in a parking for a fixed period of time in order to occupy it. The reservation depends on the architecture of the parking management system, which can be either centralized or distributed. In the first case, the reservation is often made through an application installed on an intelligent mobile device (smartphone, tablet, iPad, etc.). The user sends a request for an available place to a parking management and control system. The management system processes the request and sends a response to the user based on the data and information available on the parking status. In the second case, the use of vehicle-vehicle communication using Ad-Hoc vehicle networks (VANET) is used. There are different reservation systems for intelligent parking, we have been able to classify them into two types: booking systems using the agent approach and non-agent booking systems.

Payment system: Is the purchase transaction that effectively brings a monetary contribution for the parking service. Several payment methods are available and are divided into three classes:

- The user moves: Parking meter;

- The user does not move but performs the remote payment: payment by SMS, on a smartphone application, or in advance (reservation). The user communicates by SMS the license plate number and the code of the parking area concerned;

Payment does not require any user action or movement: payment is made by automatic recognition, via a license plate detector or a Dedicated Short-Range Communications (DSRC) device.

\section{B. Technology Trends for Smart Parking Systems Worldwide}

The statistical analysis of the published patent applications for smart parking in the ORBIT database generated several results in the order of 28,474 patented inventions.

The distribution of patent applications in the field of smart parking by country of publication (Fig. 2) reflects the potential markets for technology. Indeed, the fact that an applicant protects its patent application in a country other than the country of filing shows interest and potential profitability of that patent application in that territory. China, Japan and the United States of America remain the most attractive countries in terms of extending the protection of patent applications with 8143 families, 4913 families and 3454 families, respectively. The graph above shows that the African continent is still widely perceived as an inhospitable land for smart parking technologies. The only attractive market for this technology is South Africa by 106 families.

Fig. 3 presents the top depositors in volume on the analyzed theme. This type of representation shows the players who own the biggest portfolios in the field of smart parking. As can be seen, the leading companies in this field occupy the first places in the list of TOP patent holders (Amano, IPS, Panasonic, Dayang Parking, Robert Bosch, Hangzhou Xizi Iuk Paring System). This is confirmed by the smart parking market study published on September 19, 2018 by Market Research Future.

In most modern cities, drivers are provided with guidance systems (variable message signs, parking status displays, etc.). However, despite this, the traffic system and drivers face extreme difficulties, especially during peak hours, or at special events such as festivals. Ultimately, in many urban areas, it is tedious to find an available parking space and, when this is done, it is difficult to know if it meets the expectations of drivers and parking managers.

Thanks to the development of smart reservation-based parking systems, drivers can check the availability of parking in real time, book a place remotely and are no longer required to be physically present to perform these operations.

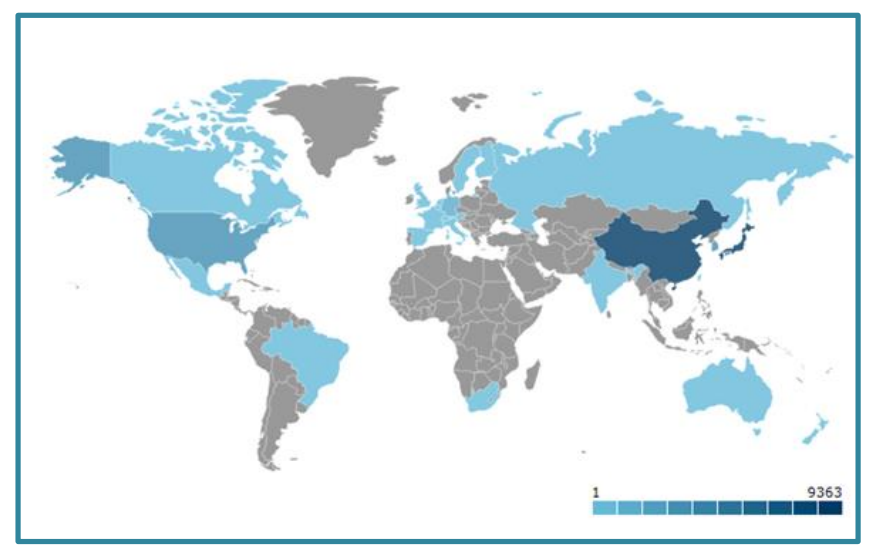

Fig. 2. Countries Producing Smart Parking Technologies.

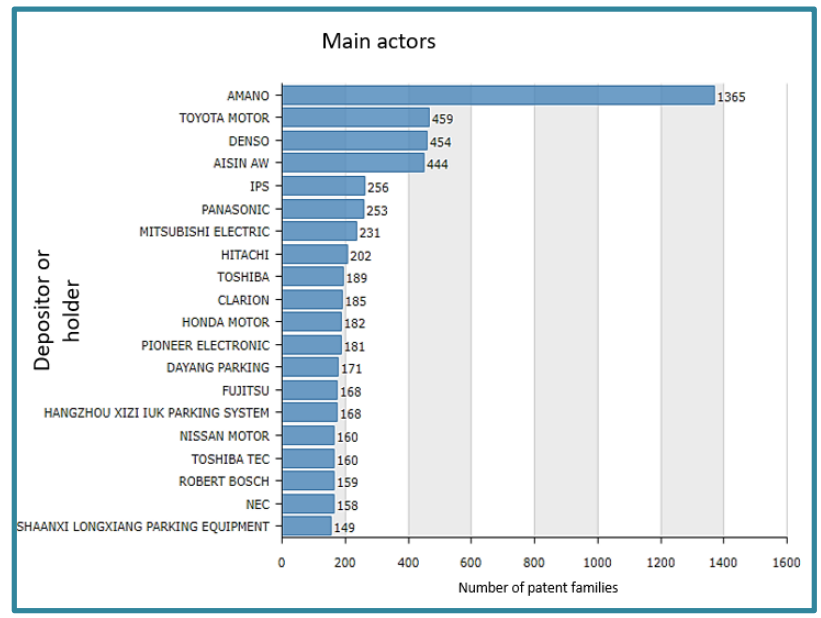

Fig. 3. Top 20 Active and Innovative Structures in the Field of Smart Parking. 
For efficient use of such a system, the driver should be informed that the target area only receives customers who have booked in advance, in order to avoid additional flows (drivers without reservations). In addition, the driver should control his parking dwell time to avoid overcharging. Another problem with reservation systems is the phenomenon of multiple-carchasing-single space, so that the customer who arrives and finds his place occupied by the last driver who has parked previously or by another who has not reserved; and no place is available in the parking, will be asked to leave without parking, which would cause frustration among drivers. Finally, the cost of implementing such a heavy solution is important, especially on the streets, given the number of equipment to be installed per lot (sensors, cameras, retractable bollards, etc.).

Based on the above findings, pricing policies are obviously an effective control tool to reduce the search for parking spaces and control parking occupancy and dwell time. Indeed, by achieving optimal occupancy of the parking (around $70 \%$ and $80 \%$ occupancy), the problems associated with reservation can be overcome. In addition, the difficulty of obtaining real-time parking information on public roads, unlike off-road parking with detection systems (sensors, cameras, etc.), makes pricing policies a powerful tool for managing supply and demand for parking in dense/very dense urban areas.

\section{Parking Pricing Policies}

Parking pricing policies constitute a key factor in influencing driver decisions and solving traffic problems without a dedicated infrastructure. In other words, effective pricing policy ensures, through financial constraint, an attractive incentive mechanism in view of the parking supply and maximizes the advantage for the parking operator. However, the adoption of a pricing policy is also a sensitive measure, as it can reduce and/or induce travel demand [34]. It has been proven that the availability of parking places at the workplace and the absence or low cost of parking greatly promote the use of personal cars [35].

Parking pricing has attracted many researchers as an important component of parking policy [2], [36]-[39]. It guarantees, by a financial constraint for the driver, the respect of the parking dwell time and is also a source of profit for the owner of the parking lot or the authorities. In this way, a consistent pricing policy should be well defined to control travel planning and absorb parking demand.

Dynamic pricing has recently entered the language of parking as a component of an effective congestion mitigation strategy. Most Parking meter offer a "static" linear hourly rate, regardless of traffic conditions and parking usage. Static rates generally favor the search for "free" or "cheap" parking spaces, which increases congestion and travel times. Essentially, dynamic pricing is about setting the correct hourly rates that will determine how long a car is parked - which will increase the turnover and availability of parking.

\section{PROPOSED SOLUTION}

The proposed solution aims to overcome reservation and guidance systems limitations. The concept combines real time pricing and reservation sharing service; thus, a driver can consult, online and in real time, parking prices within a radius of their destination, and reserve a spot in the selected parking if the services is available, otherwise, he receives the itinerary to the selected parking lot. In addition, a dynamic pricing control unit which dynamically updates the parking prices, based on real time parking occupancy and reservation requests, is integrated. In addition, the system gives drivers the opportunity of choosing an optimal parking lot based on their destination locations and other parameters (parking availability probability, walking distance, cruising time, ... etc.) subject of our previous paper.

\section{A. System Framework}

The platform connects all the parking lots in a city forming a network of parking lots as shown in Fig. 4. There are one central price control unit, one central booking center, one parking manager (authority) and multiple parking facilities throughout the city.

Driver wishing to travel to a destination, can use the platform to obtain the price of the available parking lot in optimal way. The driver's request process is as following: parker chooses his destination and set the maximum walking distance he can tolerate, expressed as a search radius value. The system responds back with price offer list of available parking lots within the fixed search radius.

To improve driver experience, the system can calculate the best alternative (optimal parking lot) based on a cost assigned to each parking lot alternative.

Driver chooses the desired parking. He can book a parking place in the select parking, if the reservation service is provided. If not, the parking itinerary is indicated.

Parking authority can adjust the relevant parking price by fixing, increasing or decreasing rates; or updates data center with reservation events. Below we describe the main components of the system:

Price control unit: is an application that run a pricing program. Its function is to control parking resource exploitation by updating prices every predefined time interval. The new prices are sent to user through the web application and virtual message sign (VMS) in each parking facilities.

Booking center: manages the parker's booking requests. In order to validate a booking request, the system check the occupancy of the selected parking. If available, the system assigns a parking place to parker after completing the payment transaction. The parker identifications (i.e., driver and car license IDs) are required to finalize the booking request. Finally, the system notifies the driver of information related to parking spot reserved and itinerary.

Data Center: stores all the data (Sensors, RFID, LPR) from all parkings in the city. It contains a pricing table with the up to date information on pricing per parking lot, occupancy table which holds the utilization data, parking location data, parking lots capacities, ... etc. It is also responsible for updating virtual message signs and public devices of pricing information and parking availability. 


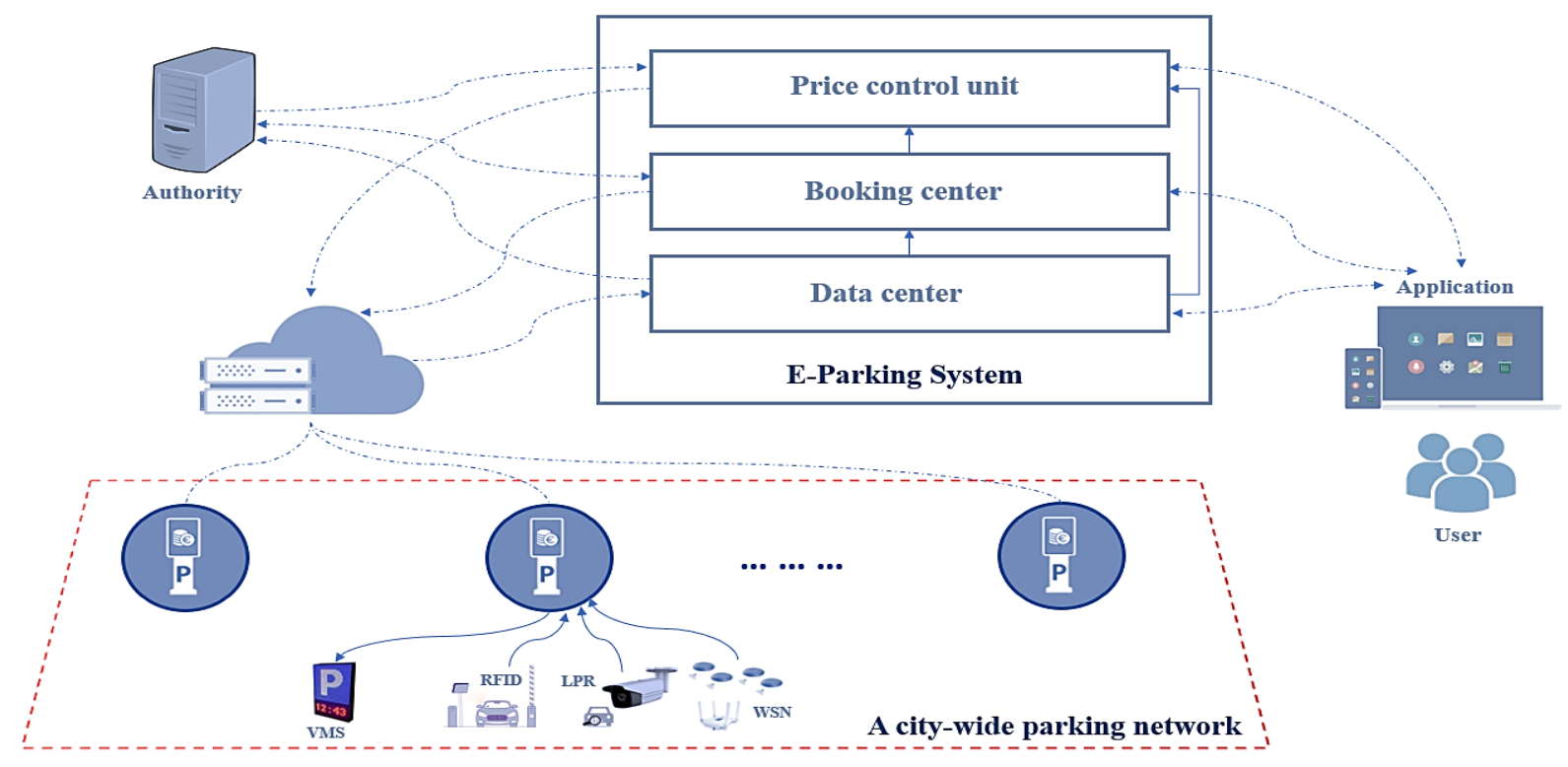

Fig. 4. e-Parking Framework.

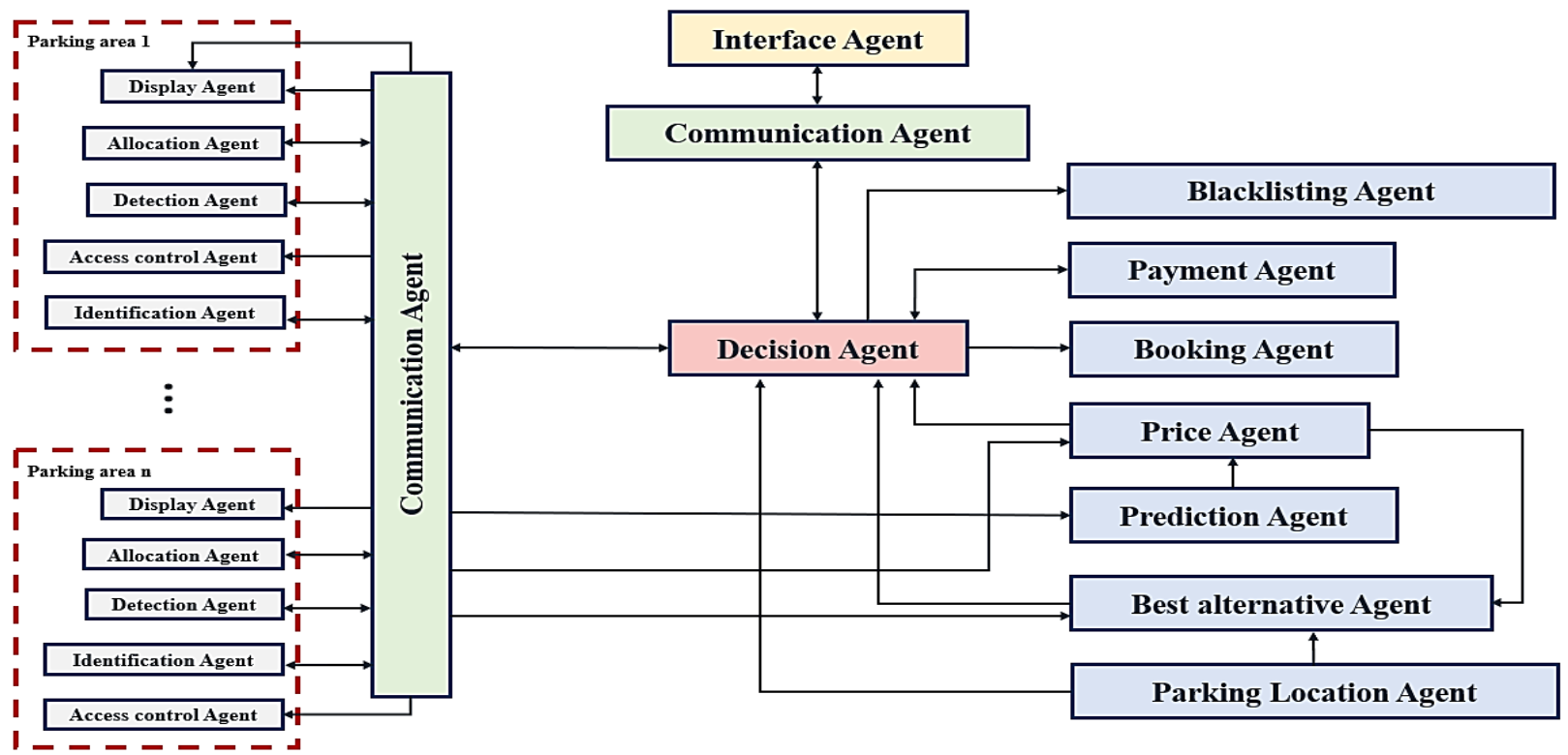

Fig. 5. Multi-Agents Architecture for Managing the Parking Network.

\section{B. Smart Parking Architecture}

As part of our work, we were interested in modelling our solution as a distributed multi-agent system. For more details about multi-agent systems, see [40], [41]. For this purpose, a first step, consists of modelling the interactions in a multi-agent system, is illustrated in Fig. 5. Each agent has a mission to perform in this interaction:

- Display agent: its role is to display the parking information messages in real time i.e. parking status, prices, etc. The display can be either locally at the parking level or on a city scale via variable message signs and web application.
- Allocation agent: As we work in a mixed environment that accepts drivers who have made or not a reservation of parking space, we will need the agent allocation to manage the parking arrival flows. Two missions can be performed by this agent, the first is to assign the available parking places to the reservation requests received; the second is to allocate parking places to drivers who come to the parking without having made a reservation. For the second case, the assignment is based on available places (detection agent) and reservation requests already validated (booking agent).

- Detection agent: Its role is to detect the parking availability by checking the status of sensors on each place and the presence of vehicles in the parking entrance and exit. 
- Identification agent: Its function is to identify the vehicle identity in parking check-point (i.e. parking entrance) via identification technologies i.e. RFID, ALPR or a combination of the two technologies.

- Access control agent: It control access/exit to/from the parking. To perform this function, this agent relay on information from detection, identification, booking and allocation agents.

- Communication agent: It ensures communication between agents located in different environments.

- Decision agent: It collects messages from all agents and makes the final actions and decisions of the system. It represents the authority or parking network manager.

- Price agent: Price agent mission is to control parking occupancy and update parking prices every predefined time interval. The new prices are calculated based on the parking availability, prediction information and reservation requests. The role of this agent is to overcome the phenomenon of multiple-car-chasingsingle space, by maintaining an optimal level of occupancy via a dynamic pricing policy. When the target occupancy level is achieved, the price agent adjusts (increase or decrease) the prices dynamically. In this way, the parking can always maintain an optimal level of availability able to satisfy its customers.

- Prediction agent: It predicts the occupancy level based on real time (detection agent) and historical occupancy (booking agent) data. Its role is to provide price agent by data necessary for price adjustment and maintain an optimal occupancy parking rate.

- Best alternative agent: It calculates the best alternative (available parking) based on a cost assigned to each parking alternative. The cost is calculated based on several parameters i.e. walking distance, parking price, parking occupancy, etc.

- Booking agent: It manages and stores the validated reservation requests and parking lots information.

- Payment agent: It manages the payment transactions for confirmed reservation requests.

- Parking location agent: Contains information about parking locations. It displays the available parking lots within the search radius, locates the user and sends the itinerary to the desired parking.

- Blacklisting agent: it stores in a black list the customers judged by the decision agent as customers prohibited from accessing the parking platform.

- Interface agent: Acts as an intermediary between car parks, users and the system, receives customer requests and displays available processing results.

This architecture guarantees the quality of service by ensuring optimal occupancy of the parking lots.

\section{IMPLEMENTATION}

In this section we discuss the implementation of the system in a real-world scenario.

The project consists in developing a web application, shown in Fig. 6, that allows users to consult, online and in real time, parking prices within a radius of their destination.

In order to evaluate the performance of our system under realistic conditions, we have chosen the metropolis of Casablanca, see Fig. 7, as test environment. Casablanca is the largest and most populated city in Morocco. It is also the largest and most important (both economic and demographic) cities in Africa. It is therefore an excellent choice and a perfect place to lead innovative pilot projects and living laboratories. In addition, it shares a context similar to that of many cities in Africa and Europe, which results in effective consequences.

The flow chart in Fig. 8 illustrates and explains the different steps that can be experienced by users:

The application user can consult the different prices of the parking lots located within the radius already defined (Fig. 9 and 10).

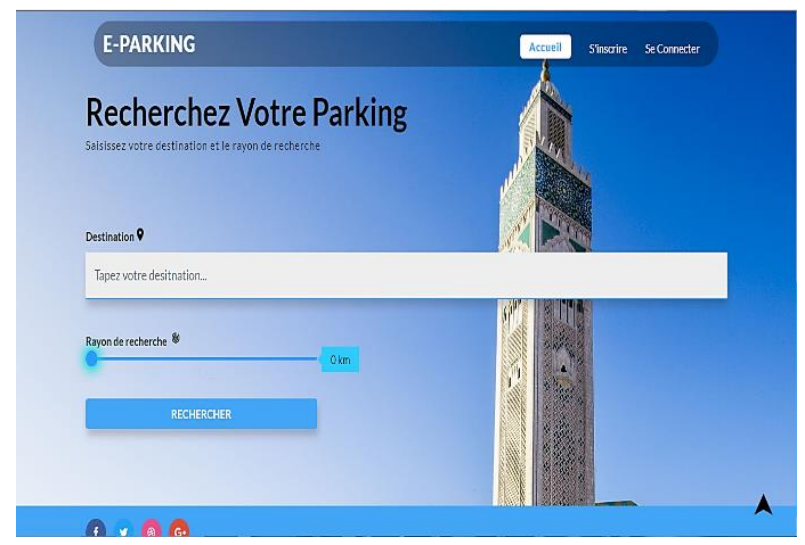

Fig. 6. e-Parking Home Page.

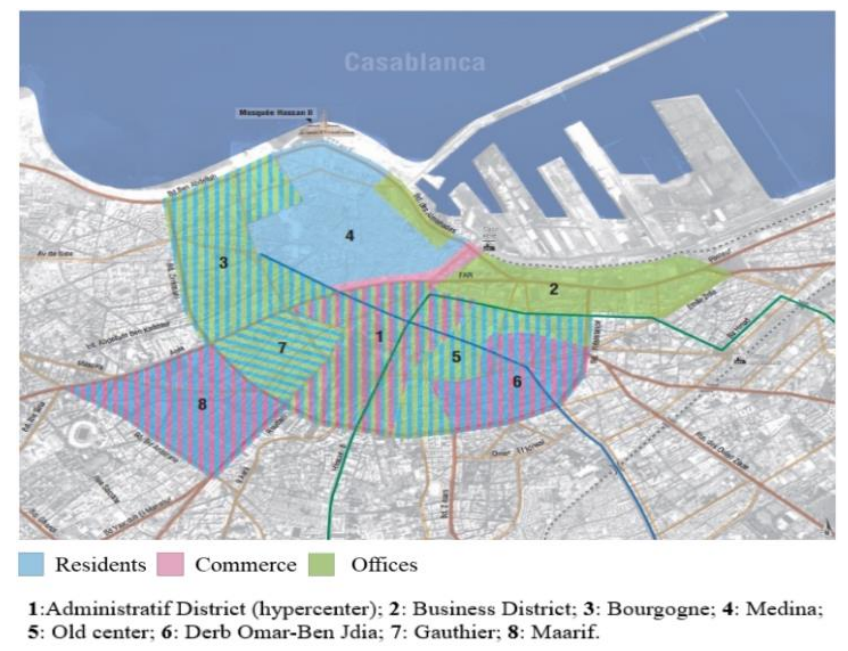

Fig. 7. Anatomy of the Urban Fabric and Activities in Casablanca. 


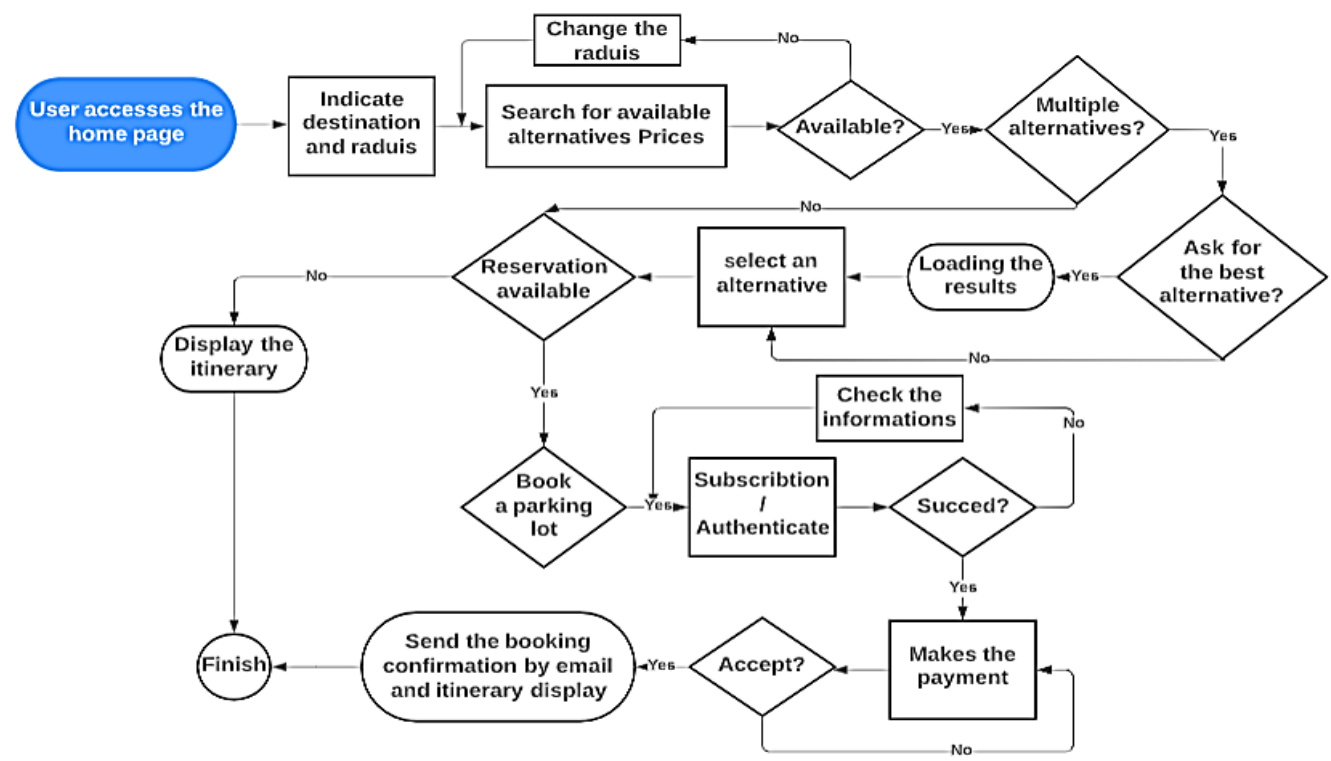

Fig. 8. e-Parking Flow Chart.

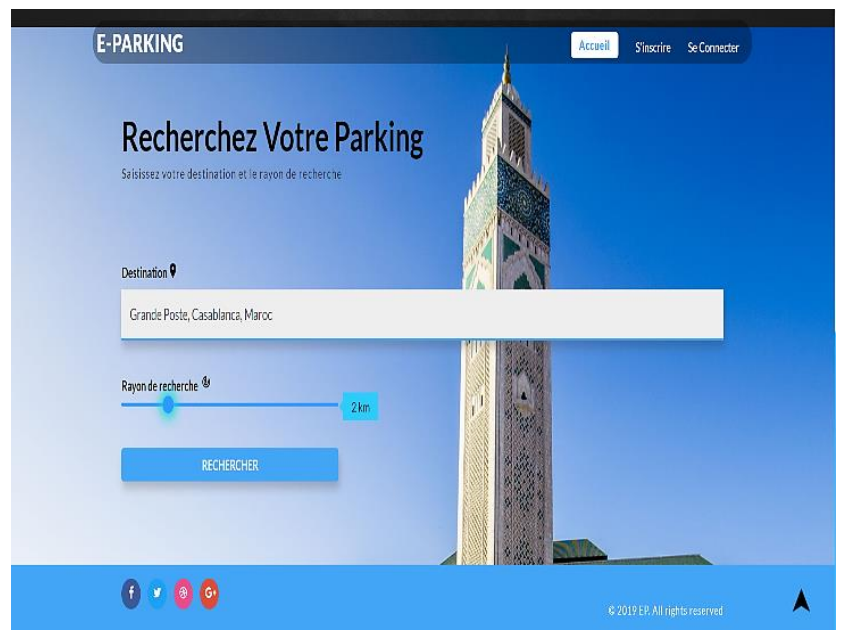

Fig. 9. Destination and Search Radius Setting.

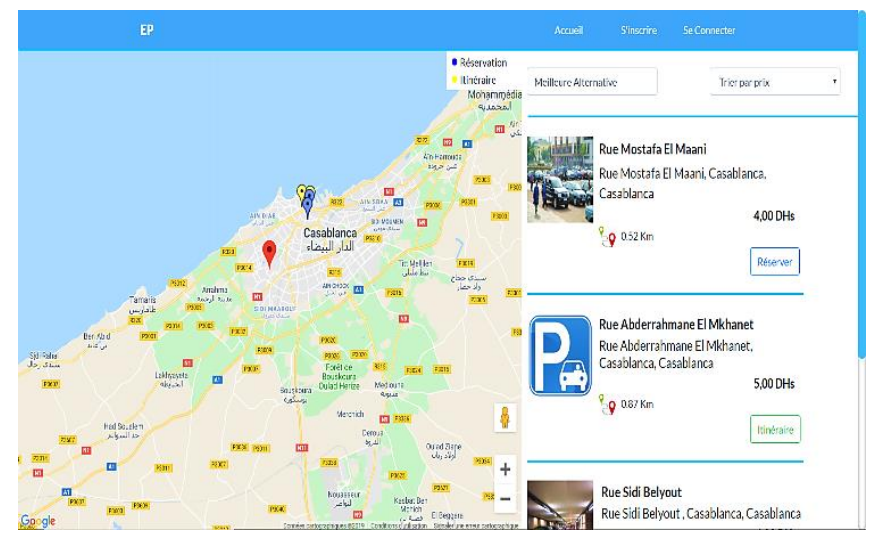

Fig. 10. Search Results.

If several alternatives (parking lots) are available, the driver can request the most optimal alternative in terms of walking distance (calculated from the previously set radius), parking fees (according to its parking time and the price on the database) and other parameters of the available parking (arrival rate, departure rate, real time occupancy rate and parking capacities).

After the most suitable alternative has been calculated, a list is generated that ranks the alternatives according to their total parking costs as shown in Fig. 11. If, among these choices, a parking lot offers a reservation service, an icon is displayed next to it to orient the driver towards the reservation service.

Otherwise the available parking is shown alone with the itinerary icon.

To make a reservation, the user should log in or create an account if he does not been registered. Registration is made by providing the user's information such as first and last name, personal details (address, telephone and email).

An email is sent to our customers who have just registered on our web application, so that they can activate their accounts (Fig. 12).

Interface, in Fig. 13, allows users to book a parking lot by indicating the arrival and departure date and time.

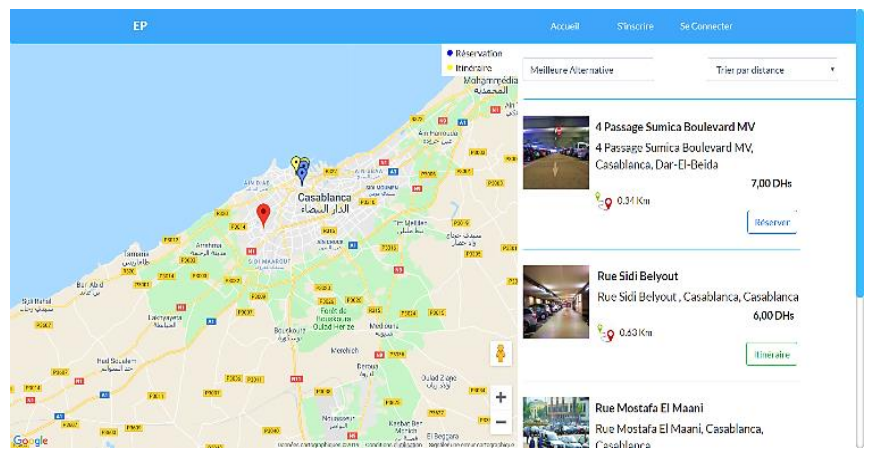

Fig. 11. Best Alternative Results. 


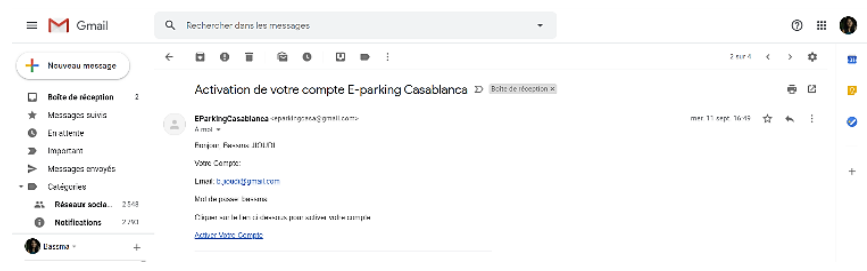

Fig. 12. Activation Email.
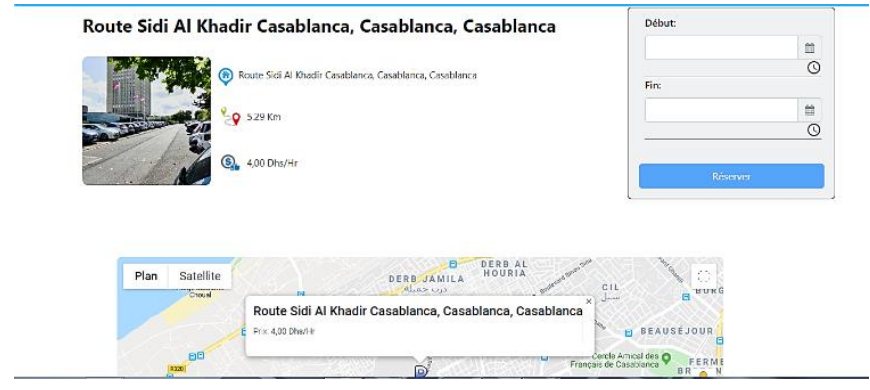

Fig. 13. Reservation Interface.

In Fig. 14, the customer has the possibility to pay parking fees online using all possible cards (visa, MasterCard, etc.).

When the payment transaction is completed, the driver receives the itinerary to the selected parking lot and the relative bill (Fig. 15).

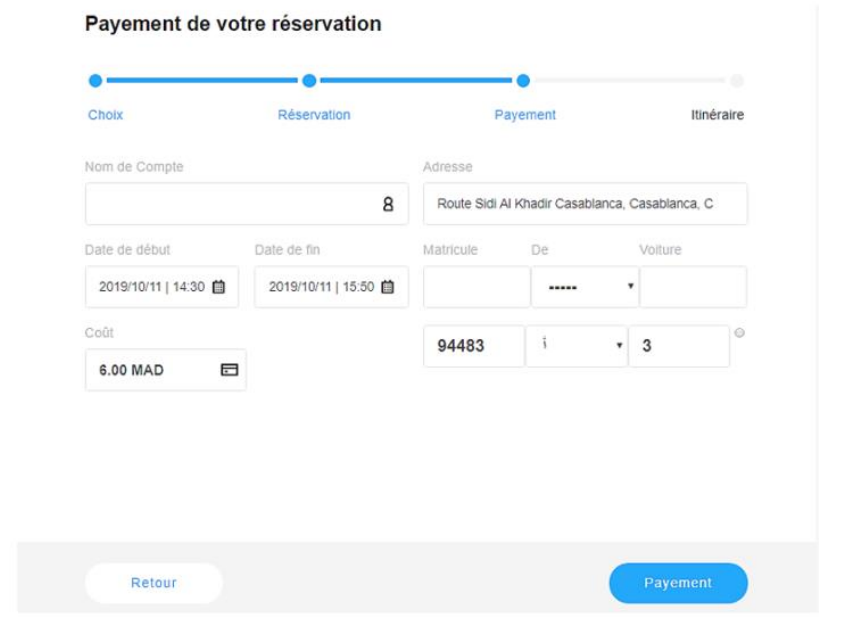

Fig. 14. Payment Interface.

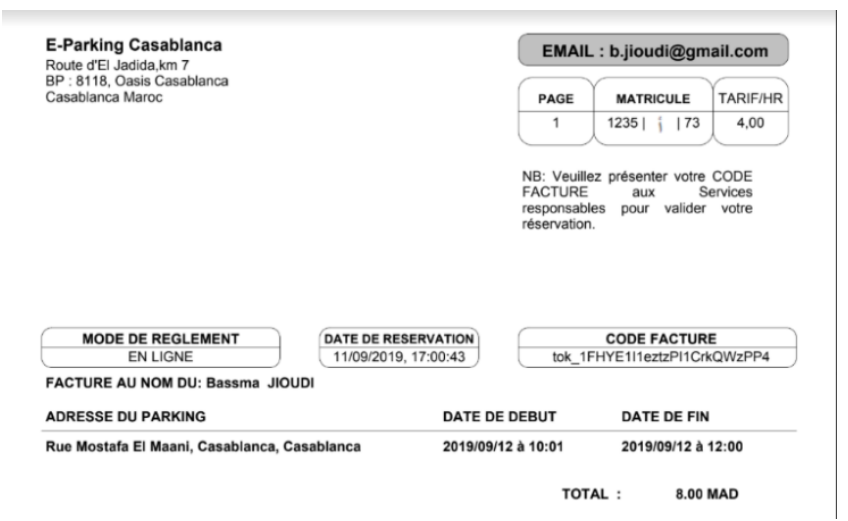

Fig. 15. Confirmation Email.

\section{CONCLUSION}

Parking is at the heart of the city, given its spatial influence and its role in urban mobility. It is also a key element in the management of its urban landscape and an essential element for effective mobility. However, parking remains a source of environmental nuisance and collapse of the quality of life. There are many challenges, such as land use, public space occupancy, economic impact, pedestrian safety and social equity. This situation becomes even more alarming in dense and ultra-dense urban environments where the availability of parking spaces significantly affects the flow of traffic. In this article, we present an analysis of smart parking concept evolution and statistical analysis of the published patent applications in this field in the ORBIT database around the world. Then, we introduce a new multi-agent architecture to manage a smart parking. Finally, we present the e-Parking, smart parking Web application developed in the Foundation of Research, Development and Innovation in Sciences and Engineering of Casablanca, Morocco (FRDISI). The proposed platform aims to improve the driver experience by combing real time pricing and reservation sharing service.

Although the main objectives of our project are achieved, the application developed could be enriched by other advanced features and improvements as the integration of multimodal systems to draw driver attention on other means of transportation available in urban environment. We also plan to communicate with parking meters to integrate on-street parking into our applications.

We have started another work with the city of Casablanca, which consists in identifying and determining the behavior of drivers and visiting drivers in the city of Casablanca. This profiling project aims to adapt the solutions proposed in the field of mobility to the reality experienced and to the actors of mobility and all stakeholders at city level.

\section{ACKNOWLEDGMENT}

The authors would like to thank the municipality of Casablanca-Morocco, for kindly providing the parking dataset used in this research.

\section{REFERENCES}

[1] F. Galatioto and M. C. Bell, "Simulation of the illegal double parking: quantifying the traffic and pollutant impacts," IV Int. SIIV Congr., 2007.

[2] D. C. Shoup, "Cruising for parking," Transp. Policy, vol. 13, no. 6, pp. 479-486, Nov. 2006.

[3] R. E. Barone, T. Giuffrè, S. M. Siniscalchi, M. A. Morgano, G. Tesoriere, "Architecture for parking management in smart cities", IET Intell. Transp. Syst., vol. 8, no. 5, pp. 445-452, 2014.

[4] M. Strasser, D. Mauser, and S. Albayrak, "Mitigating traffic problems by integrating smart parking solutions into an interconnected ecosystem," in 2016 IEEE Symposium on Computers and Communication (ISCC), 2016, pp. 32-37.

[5] I. G. B. B. Nugraha and F. R. Tanamas, "Off-street parking space allocation and reservation system using event-driven algorithm," 2017 6th International Conference on Electrical Engineering and Informatics (ICEEI), Langkawi, 2017, pp. 1-5.

[6] J. Cherian, J. Luo, H. Guo, S.-S. Ho, and R. Wisbrun, "ParkGauge: Gauging the Occupancy of Parking Garages with Crowdsensed Parking Characteristics," in 2016 17th IEEE International Conference on Mobile Data Management (MDM), 2016, vol. 1, pp. 92-101.

[7] D. Calderone, E. Mazumdar, L. J. Ratliff and S. S. Sastry, "Understanding the impact of parking on urban mobility via routing 
games on queue-flow networks," 2016 IEEE 55th Conference on Decision and Control (CDC), Las Vegas, NV, 2016, pp. 7605-7610.

[8] K. C. Mouskos, J. Tvantzis, D. Bernstein, and A. Sansil, "Mathematical formulation of a deterministic parking reservation system (PRS) with fixed costs," in 2000 10th Mediterranean Electrotechnical Conference. Information Technology and Electrotechnology for the Mediterranean Countries. Proceedings. MeleCon 2000 (Cat. No.00CH37099), 2000, vol. 2, pp. 648-651 vol.2.

[9] R. C. Larson and K. Sasanuma, "Congestion Pricing: A Parking Queue Model," Massachusetts Institute of Technology. Engineering Systems Division, Working Paper, Aug. 2007.

[10] O. Cats, C. Zhang, and A. Nissan, "Survey methodology for measuring parking occupancy: Impacts of an on-street parking pricing scheme in an urban center," Transp. Policy, vol. 47, pp. 55-63, Apr. 2016.

[11] United nations department for economic and social affairs, united nations e-government survey 2018. S.1.: united nations, 2019.

[12] "Centre d'Etudes et de Recherches Démographiques.". Available: https://www.hcp.ma/Centre-d-Etudes-et-de-RecherchesDemographiques_a735.html.

[13] "Démographie marocaine-Dissertation - 30062 Mots.". Available: https://www.etudier.com/dissertations/D\%C3\%A9mographieMarocaine/48607050.html.

[14] Sandra Breux and Jérémy Diaz. 2017. La ville intelligente : origine, définitions, forces et limites d'une expression polysémique. Institut national de la recherche scientifique-Centre Urbanisation Culture Société.

[15] Maria-Lluïsa Marsal-Llacuna, Mark Evan Segal, The Intelligenter Method (I) for making "smarter" city projects and plans, Cities, Volume 55, 2016, Pages 127-138, ISSN 0264-2751,

[16] Bhagya Nathali Silva, Murad Khan, Kijun Han, Towards sustainable smart cities: A review of trends, architectures, components, and open challenges in smart cities, Sustainable Cities and Society, Volume 38, 2018, Pages 697-713, ISSN 2210-6707,

[17] Albino, V., Berardi, U., \& Dangelico, R. (2015). Smart cities: Definitions, dimensions, performance, and initiatives. Journal of Urban Technology, 22(1), 3-21. http://dx.doi. org/10.1080/10630732.2014. 942092.

[18] "Communication : Envisager sa politique de stationnement d'un point de vue «smart»? Quelques initiatives d'utilisation de nouvelles technologies dans la gestion du stationnement (03-2016).”. Available: https://www.uvcw.be/articles/3,10,2,0,6399.htm. [Accessed: 24-Oct2019].

[19] I. G. B. B. Nugraha and F. R. Tanamas, "Off-street parking space allocation and reservation system using event-driven algorithm," in 2017 6th International Conference on Electrical Engineering and Informatics (ICEEI), 2017, pp. 1-5.

[20] M. Liu, J. Naoum-Sawaya, Y. Gu, F. Lecue, and R. Shorten, "A Distributed Markovian Parking Assist System," IEEE Trans. Intell. Transp. Syst., vol. 20, no. 6, pp. 2230-2240, Jun. 2019.

[21] S. Ma, O. Wolfson, B. Xu, "UPDetector: Sensing parking/unparking activities using smartphones", Proc. ACM Int. Workshop Comput. Transp. Sci., pp. 76-85, 2014.

[22] M. Rinne, S. Torm" a, and D. Kratinov, "Mobile crowdsensing of parking " space using geofencing and activity recognition," in 10th ITS European Congress, Helsinki, Finland, 2014, pp. 16-19.

[23] V. Koval, V.Turchenko, V. Kochan, 2003, Smart License Plate Recognition System based on Imaging Processing using Neural Network.

[24] M. Gallo and F. Montone, "The potential effects of real-time parking (RTP) systems on cruising for parking and greenhouse gas emissions," 2017 IEEE International Conference on Environment and Electrical Engineering and 2017 IEEE Industrial and Commercial Power Systems Europe (EEEIC / I\&CPS Europe), Milan, 2017, pp. 1-6.
[25] A. Braga Reis, S. Sargento and O. K. Tonguz, "Smarter Cities With Parked Cars as Roadside Units," in IEEE Transactions on Intelligent Transportation Systems, vol. 19, no. 7, pp. 2338-2352, July 2018.

[26] K. Hassoune, W. Dachry, F. Moutaouakkil and H. Medromi, "Smart parking systems: A survey," 2016 11th International Conference on Intelligent Systems: Theories and Applications (SITA), Mohammedia, 2016, pp. 1-6.

[27] P. Sotres, C. L. d. 1. Torre, L. Sánchez, S. Jeong and J. Kim, "Smart City Services Over a Global Interoperable Internet-of-Things System:The Smart Parking Case," 2018 Global Internet of Things Summit (GIoTS), Bilbao, 2018, pp. 1-6.

[28] I. G. B. B. Nugraha and F. R. Tanamas, "Off-street parking space allocation and reservation system using event-driven algorithm," 2017 6th International Conference on Electrical Engineering and Informatics (ICEEI), Langkawi, 2017, pp. 1-5.

[29] Y. Geng and C. G. Cassandras, "New "Smart Parking" System Based on Resource Allocation and Reservations," in IEEE Transactions on Intelligent Transportation Systems, vol. 14, no. 3, pp. 1129-1139, Sept. 2013.

[30] M. Alam, B. Fernandes, J. Almeida, J. Ferreira and J. Fonseca, "Integration of smart parking in distributed ITS architecture," 2016 International Conference on Open Source Systems \& Technologies (ICOSST), Lahore, 2016, pp. 84-88.

[31] P. M. d'Orey, J. Azevedo and M. Ferreira, "Exploring the solution space of self-automated parking lots: An empirical evaluation of vehicle control strategies," 2016 IEEE 19th International Conference on Intelligent Transportation Systems (ITSC), Rio de Janeiro, 2016, pp. 1134-1140.

[32] T. Lin, H. Rivano and F. Le Mouël, "A Survey of Smart Parking Solutions," in IEEE Transactions on Intelligent Transportation Systems, vol. 18, no. 12, pp. 3229-3253, Dec. 2017.

[33] M. S. Kuran, A. Carneiro Viana, L. Iannone, D. Kofman, G. Mermoud and J. P. Vasseur, "A Smart Parking Lot Management System for Scheduling the Recharging of Electric Vehicles," in IEEE Transactions on Smart Grid, vol. 6, no. 6, pp. 2942-2953, Nov. 2015.

[34] Nourinejad, M., and M. J. Roorda. 2017. Impact of hourly parking pricing on travel demand. Transportation Research Part A: Policy and Practice 98 (April):28-45.

[35] “BAnQ numérique.”. Available: http://numerique.banq.qc.ca/.

[36] L. D'Acierno, M. Gallo, and B. Montella, "Optimisation models for the urban parking pricing problem," Transp. Policy, vol. 13, no. 1, pp. 34 48, Jan. 2006.

[37] Z. (Sean) Qian and R. Rajagopal, "Optimal occupancy-driven parking pricing under demand uncertainties and traveler heterogeneity: A stochastic control approach,” Transp. Res. Part B Methodol., vol. 67, pp. 144-165, Sep. 2014.

[38] A. Millard-Ball, R. R. Weinberger, and R. C. Hampshire, "Is the curb $80 \%$ full or $20 \%$ empty? Assessing the impacts of San Francisco's parking pricing experiment," Transp. Res. Part Policy Pract., vol. 63, pp. 76-92, May 2014.

[39] S. Mathur et al., "ParkNet: Drive-by Sensing of Road-side Parking Statistics," in Proceedings of the 8th International Conference on Mobile Systems, Applications, and Services, New York, NY, USA, 2010, pp. 123-136.

[40] M. Dell'Orco and D. Teodorović, "Multi Agent Systems Approach to Parking Facilities Management," in Applied Research in Uncertainty Modeling and Analysis, N. O. Attoh-Okine and B. M. Ayyub, Eds. Boston, MA: Springer US, 2005, pp. 321-339.

[41] F. Michel, J. Ferber, A. Drogoul, J. Ferber, and A. Drogoul, "MultiAgent Systems and Simulation: A Survey from the Agent Community's Perspective," Multi-Agent Systems, 08-Oct-2018. 